\title{
Perceived Effects of Burnout on Patients and its Management among Nurses in the Intensive Care Unit and Emergency Department of a Rwandan University Teaching Hospital
}

\author{
Emeline Umutoni Cishahayo ${ }^{1 *}$, Marie Jeanne Tuyisenge ${ }^{1}$, Marie Josée Mwiseneza ${ }^{1}$, Ruth Sego ${ }^{1,2}$, Busisiwe
} Rosemary Bhengu ${ }^{1,2}$

\author{
${ }^{1}$ School of Nursing and Midwifery, University of Rwanda, College of Medicine and Health Sciences, Kigali, Rwanda \\ ${ }^{2}$ Rory Meyers College of Nursing, New York University, New York, USA
}

*Corresponding author: Emeline Umutoni Cishahayo. School of Nursing and Midwifery, College of Medicine and Health Sciences, University of Rwanda, Remera Campus, 11 KG 47, Kigali, Rwanda. Email: cishahayoemeline@, gmail.com

\begin{abstract}
Background

The level of burnout among nurses working in the Intensive Care Unit (ICU) and Emergency Department (ED) is high, which adversely affects health and work-related outcomes for both nurses and patients. Little is known about burnout among ICU and ED nurses in Rwanda. Objective

To explore the perceived effects of burnout among nurses and its management at a referral hospital in Rwanda.

Methods

A qualitative study design was carried out using focus groups. A purposive sample of six ICU and six ED nurses were recruited from the referral hospital in the capital city of Kigali. The discussions were audio-recorded in Kinyarwanda, transcribed verbatim into English and analysed inductively using thematic analysis.

Results

Burnout among the 12 nurses was high and the five main themes namely, high burnout, the Variability of care, Incomplete care, Erratic care and Improving situation to prevent burnout. Conclusion

The results of this study indicated that burnout is high between the ICU and ED study population and nurses need to be taken care of too. A good working environment addressing adequate staffing, specialty training, operational materials, and social activities are needed to improve unit functioning, and patient satisfaction and safety.
\end{abstract}

Rwanda J Med Health Sci 2019;2(2):147-153.

Keywords: Burnout, nurses, Intensive Care Unit, emergency department, patient care

\section{Background}

Many healthcare professionals are burned out.[1] Fortythree per cent of nurses had a high level of emotional exhaustion and physicians were at $50 \%$. Burnout is not only characterised by emotional exhaustion, but also high depersonalization (cynicism), and a low sense of personal accomplishment.[1] A 2017 systematic review involving 25 studies revealed that the prevalence burnout rate among ICU professionals ranged from $6 \%$ to $68 \%$, higher than the average health care worker, [2,3] and similar to the challenges for ED nurses. [4] Burnout significantly affects the quality of care and safety (patient and nurse) healthcare costs, turnover and lower work effort, patient satisfaction, and personal consequences to healthcare professionals.[1]
Burnout can be described as a condition of reduced energy of an individual and has three dimensions, according to the Maslach Burnout Inventory published in 2006; [5] Emotional exhaustion; Depersonalization; and reduced Personal accomplishment. Emotional Exhaustion is the lack of energy and motivation of an individual for work. Depersonalization is treating people who are beneficiaries of a given service indifferently and criticising colleagues' attitudes and behaviours. Reduced personal accomplishment is the inability to be competent and achieve feelings of insufficiency after evaluating one's performance.[6] Findings from their more recent research, Leiter and Maslach[7] revealed that a high level of cynicism appeared to reflect burnout better than high emotional exhaustion alone. 
Kompanje provided specific situations whereby nurses and physicians were burnt out because of the distress at work and becoming progressively more cynical. [6] A nurse showed cynicism toward his patients as if they were "disposable inhumane objects"(p1). Another nurse felt disengaged a feeling of no personal accomplishment, and cynic toward her suffering patients. Working in the ICU and ED is particularly distressing due to the severity of the patients' conditions and attendant high mortality rate, and dealing with challenging traumatic and ethical issues daily.[4,7]

Burnout among nurses affects not only nurses but also the patients, colleagues and the organisation. [3,8] Burnout among nurses was found to decrease the quality of care provided,[1] and increased the rate of hospital-acquired infections, particularly surgical and urinary tract infections, [9] and patient mortality rate. [10] Furthermore, the perceived quality of interpersonal teamwork declined[11] is affected daily. A high level of burnout among nurses causes job dissatisfaction and leads to high nurse turnover, thus creating staff shortage and more distress.[9]

The first burnout research in the 1980s used qualitative research to explore the phenomenon [6], and since there is limited knowledge on this topic in Rwanda, a qualitative study was thought to be an appropriate approach. One cross-sectional study was conducted by the author,[unpublished] and the results indicated that the burnout level was high among ICU and ED nurses. However, there appears to be no known study conducted on the effects of nurse burnout and its consequences in Rwanda. This study aimed to explore burnout between ICU and ED nurses, its perceived effects on patients, and potential solutions at one of the referral hospitals in Rwanda.

\section{Methods}

\section{Design}

A descriptive qualitative design was used to explore the concept of burnout among nurses, its perceived effect on patients, and potential solutions. The study was conducted in the ICU and ED at one of the referral hospitals in Rwanda in a period of one month from February to March 2017.

\section{Participants recruitment}

A purposive sampling strategy was used to target registered nurses in two units. Six nurses from the ICU participated in one focus group, and six nurses from the ED participated in a second focus group. Nurses were working in ICU or ED, with at least one year or more work experience in their speciality field, were included in the study. The investigator conducted the focus group discussions.

\section{Measures}

A semi-structured interview guide was used to gather data from the two focus groups. The guide had been developed from an in-depth review of the current literature and two experts in the area of critical care nursing. The guide included open-ended and probing questions to foster more opportunities for participants to express feelings, attitudes, and thoughts about burnout in their high-stress work environment. The discussions were conducted in Kinyarwanda or French, depending on the participants' preference as these languages are used interchangeably in Rwanda.

The data was later transcribed verbatim into English. The interview guide began with broad questions and contained the following questions: (1) How would you rate burnout level among nurses working in the unit? Why do you think so? (2) How would you compare burnout here with other units? Why? What do you think exposed ICU and ED nurses to burnout, compared to nurses on other units? (3) How do you think the burnout of nurses will affect patients' care? (4) How could this situation be improved? (5) Is there anything else you would like to add?

\section{Data collection}

The investigator and a moderator (research assistant) conducted the focus group discussions at the nurses' work, though outside of duty hours to avoid interruptions to attend to patient care or help a colleague on the unit. One focus group discussion occurred during the day in the ICU following night duty, and the other focus group met in the ED during the night following day duty. The focus group discussions took between 30 to 90 minutes and were conducted in the unit staff rooms. The room was calm, quiet, safe, comfortable, well lit and ventilated. During the discussion, participants sat facing each other in order to promote mutual interaction, maintain eye contact, and discussion.

The moderator, experienced in qualitative data collection, moderated the focus group discussions. The investigator operated the audio recorder and took field notes on how participants responded and reacted during the discussions. Prior to commencement, the moderator and the participants set ground rules to promote mutual respect and thoughtful exchange. Probing, clarifying and summarising were strategies used by the moderator during the focus group discussions to encourage respondents to give more information and continued until data saturation was reached. A small gift of airtime was given to the participants, as they had to stay beyond their work hours to complete the study.

\section{Trustworthiness}

Several strategies were used to ensure trustworthiness of the qualitative data. [12] The investigator transcribed verbatim the audiotapes that were initially done in Kinyarwanda and French and then translated into English. The investigator documented the decision process and used audit trails, to assure transferability to other contexts. To further add credibility, an experienced 
qualitative supervisor (last author) overseeing the study, reviewed the transcripts and verified the codes and data analysis.

Furthermore, a peer debriefing was done whereby the research methodology, data analysis and interpretations were done with skilled researchers not involved in the study. Dependability, achieved by using participants from two slightly different units (ICU and ED) provided critical care for consistency. Confirmability was achieved when the lead author did member checking with participants, which verified that the themes reflected the data gathered during the focus group discussions. Authenticity was obtained through the direct quotes of the lived experiences of nurses working in critical care units and emergency department.

\section{Data analysis}

Data were analysed using the Thematic Analysis as outlined by Braun and Clarke,[13] and defined as, "A method for identifying, analysing and reporting patterns within data." (p. 79). The thematic analysis included six phases: Data from the two focus group discussions were transcribed verbatim, read entirely and reread, searching for meanings and patterns. Initial coding was done through structured coding which consisted of labelling the data and organising it into meaningful groups. A pattern coding took place whereby the researcher organised the labels given to data in the initial coding into broad categories, then subcategories based on information with similar content or meanings, known as the similarity principle. The researchers reviewed the categories and themes to see if they fit the narrative material collected in the focus groups. The refined themes were identified as commonalities, not based on individual nurses, but across the nurses working in ICU and ED. The final analysis involved three themes and seven subthemes. Vivid examples given by the participants were integrated into the text in italics to support the final manuscript.

\section{Ethical considerations}

Permission was granted by the University of Rwanda, College of Medicine and Health Sciences' Institutional Review Board (IRB) and the participating institution.

Participation was voluntary, all consent forms were signed, and anonymity was ensured in the dissemination of the findings.

\section{Results}

Five themes emerged from the data, namely, high burnout, variability of care, incomplete care, erratic care and improving situation to prevent burnout.

\section{Theme 1: High burnout}

On initial discussion, participants perceived themselves to have high burnout, which they attributed to staff shortage compounded by high workload amid patients of high acuity, unpredictable hours and patient flow and non-recognition of extra hours they worked. Furthermore, these participants would go for 24 hours without meeting their families whom they left sleeping to go to work and found asleep coming back. The participants demonstrated these issues both in Emergency and ICU as the following excerpts:

The number of patients we receive does not match the number of nurses who have to take care of them; there is a shortage of staff. We don't have a fixed number of beds for our patients, and we keep receiving them (1ER). You work extra hours; you cannot know the time for work or not; you work without resting (2ER). We work many hours, and you always have two patients to take care of, and they are in critical condition (1ICU).... nurses in ICU start from 7 am to 7 pm, or from 7 pm to 7 am without having a break, you get tired (3ICU). Furthermore, those worked extra hours we work are not recognized, and they don't even consider the high workload ... (3ICU). You can find yourself not meeting your family members in 24 hours; you leave home early morning while they are asleep and you come back while they sleep again (2ED).

\section{Theme 2: Variability in care}

Participants expressed the impact of burnout on the variability of patient care, necessitating prioritisation of patients, based on who is more critical, but at the detriment of others, as expressed by the following excepts:

You delay giving care to the patient (1ED). ... If you have 2 patients that need suctioning at the same time and yet 1 person has to help them, one patient may suffer from the problem of airway obstruction and even develop asphyxia because the suctioning was not done on time (4ICU).

Due to the shortage, we prioritise care, we provide some care, and others remain (2ER). If a patient develops cardiac arrest, you focus on that one with cardiac arrest, you will be busy with CPR, and maybe another patient may develop a problem, and that time you will not be aware of (4ED). We are no longer helping patients appropriately because we are exhausted.

\section{Theme 3: Incomplete care}

Based on instability and crowding of the emergency and allocation of patients beyond the standard 1:1 in ICU, the participants felt that they could not complete care or perform comprehensive care as expected in ICU. This is compounded by a shortage of staff, long shift hours without even a tea break, and instability in the emergency room in the face of high acuity patients. The participants reported that these factors contributed to their exhaustion and underperformance. They expressed these concerns in the following excerpts:

We receive patients without stopping (1ER) ... We provide some care, and others remain, and due to many patients and fatigue (2ER), it is obvious when you are tired you can't work properly (1ER). We get tired. Care is limited. We provide some care and others remain and due to many patients and fatigue (2ER). You get exhausted, and you do not provide full nursing care (1ICU). Normally in ICU, it should be 1 patient for 1 
nurse so that she could be given fully needed care. Again due to many hours we work from 7 am to 7 pm you get exhausted (2ICU). You maximise to $80 \%$ but as you understand if you do not work well at $100 \%$ as it was supposed to be that $20 \%$ remaining can harm (4ICU). On our side, we have the will to work very well at $100 \%$, but when it becomes impossible, it is not because of you but because of the high workload and from that you do what you can (4ICU).

\section{Theme 4: Care is erratic}

Participants perceived exhaustion from high burnout, which they professed to suffer, to contribute to errors in their care over and above incomplete care. Two of the participants in both focus groups felt that they do not find any effect, they, however, admit to performing $80 \%$ at the same time raising concern that the remaining $20 \%$ can cause harm. However, they found themselves compelled to continue working whether tired or not. This they expressed in the following excerpts:

Two patients both in critical condition and every patient need close monitoring (4ICU). High level of burnout can cause errors; you cannot give a drug properly, causes needle sticks; in fact, it causes many problems (1ER). The patient may not be turned because you are tired and at that time the patient will be affected (2ICU). You do not perform your job very well (5ICU).

But to me, there is no effect on patient care because you do your best to do what is supposed to be done to the patient even though it is not done a hundred percent (2ICU). ... you have to finish your tasks being tired or not. We do our best to finish our tasks, but you cannot work well at 100\% (4ICU). In fact, we do our best even though we are exhausted we keep working, but you delay to give care to the patient (1ER).

Theme 5: Improving situation to prevent burnout

In order to protect patients from burnt-out nurses, participants recommended improving working conditions for nurses working these units, such as, regular hours, appropriate staff-patient ratios, staff motivation and capacity building, in addition to, provision of necessary equipment that is functional and not broken. Recognition of extra hours in terms of extra payment was identified as one of the motivators that could energise them and even attract other nurses to ICU or ER to the solution of staffing problems. Participants expressed their sentiment as follows:

To improve the situation, the first thing is that each nurse in ICU... should have one patient to take care of. ... and hours of work should be respected (7ICU). Increase the number of staff and work recommended hours (1ED). Provide all material and equipment that works properly (9ICU). Give motivation to nurses and recognise extra hours worked (9ICU). Motivation will play on ourpsychology (7ICU). ICU nurses should be paid more than other nurses working in other units so that others may not fear to come working in ICU (1ICU).

\section{Subtheme: Proper resource management}

Improving knowledge and skills utilisation specific to ICU would give nurses more confidence, job satisfaction, and improve patient outcomes. Two ICU nurses explained:

Give us training, because to come and work here in ICU, we arrange ourselves. They give us training on Basic Life Support, but really, someone who does critical care and trauma nursing should be the one to work in ICU(7ICU).

The nurses expressed a need for more personal accomplishment; to reduce the feeling of insufficiency and increase job performance.

Provision of necessary equipment that is functional and not broken can not be underestimated. Provide all material and equipment that works properly (9ICU).

\section{Staff motivation}

The ICU and ED participants would like more time for activities outside the work time in the high-stress units in order to motivate staff. Two ED nurses offered the following solutions:

The first solution I propose is to work recommended hours; then we can have time for rest and time for sport (1ED). Create time for nurses, such as, once or twice a year for people to meet and exchange ideas to manage burnout. For instance, people can get out for a picnic. Organise a visit for them to share issues that they face at work, in order for them to change the environment and improve staff motivation, and offer airtime (3ED).

Nurses could become part of the solution by involvement in staff scheduling.

\section{Discussion}

The results of this study in Rwanda indicated that nurses in ICU and ED perceived high burnout among themselves. The high burnout is similar to other studies conducted in Africa in similar settings.[14-20] These participants attributed burnout to overburden with responsibilities of high acuity patients and unpredictable work environment while faced with staff shortage and irregular hours. Moreover, they identified a lack of motivation as in training and recognition of their extra effort. Various other studies have found a high workload as a predictor of burnout,[1,15-23] or job demands.[24] In contrast, however, a study conducted in an ICU in Portugal found no correlation between burnout and workload. [24]

As a result, exhaustion was repeatedly mentioned as a contributory factor to burnout with ICU nurses as in other studies.[17] This factor was seen to affect the quality of patient care because they claimed their care was not comprehensive/holistic as expected in ICU where allocation is individual patient care versus task-oriented care in other units which they exemplified in the study as "only giving medicine". Individual patient care affords comprehensive care from specialised care, integration of activities of daily living, including psychosocial care 
accommodating the family.

Furthermore, the participants saw the quality of care being affected by the variability of care among patients under their care due to delays in reaching the second patient. They were compelled to prioritise among the patients but, because these patients were both of high acuity, care became in vain on the other patient; hence patients would complicate, often without even being seen.

Participants found their care also to be fraught with errors because they were exhausted from long hours and demotivation from lack of training, lack of recognition of their efforts including lack of operational equipment. This factor affected the quality of care and caused harm to patients; for example, they would give medication inaccurately including increased incidence of needle stick injuries.

There is a need to protect patients from burnt out nurses who have the good intention of quality patient care from their expression but incapacitated by the factors above. Participants from the study have proposed reasonable strategies, such as increasing the number of staff, so the ICU nurse to patient ratio would be 1:1. Similarly, a study conducted in Brazil showed that improved work conditions, such as adequate staffing helped prevent burnout and thus resulted in improved patient outcomes.[28] In contrast, a study conducted in South Africa showed that personal stress was a better predictor of burnout than job satisfaction, and indicated a need to develop staffing and coping strategies within contexts. [19] Participants further recommended that ICU nurses be paid extra with an additional benefit of attracting other nurses to ICU to solve the staffing issue as was the case in Nigeria and South Africa.[18]

Participants recommended unit-specific specialty training, other than just Basic Life Support (BLS). Similarly, in South Africa, specialised training increased job satisfaction and decreased burnout levels. [14] Staff was more likely to suffer from both Emotional exhaustion and Depersonalization if they had not received specialised job training.[14] In Egypt, improved training and skills utilisation increased job satisfaction, [20] and may have increased the Personal accomplishment (the third component of burnout) through communication with peers and management.

Nurses receive little recognition for performing their duties, and that can be difficult and result in lack of energy.[29] In contrast, the participants in this study did not mention conflict among the nurses or bullying, as seen in other research, [30] doctor and nurse conflict, or nursing hierarchy issues.[16] Nurses also requested sufficient materials and equipment that functions properly, which has been shown in Brazil to help prevent burnout.[31]

It appears that witnessing pain and suffering requires mental balance and a life outside of work.[32] A study conducted in Iran discovered relaxation exercises, such as yoga or mindfulness were effective antidotes to manage burnout among ICU nurses.[33] Other coping strategies include social support, relaxation time, good leadership and counselling. [7,34,35] Basic social support is met through interaction with others. [34] Similarly, the participants of this study also mentioned these issues as a solution to their burnout. In Rwanda, Friday at 3 $\mathrm{pm}$ is a government-mandated time to begin sport! The nurses who work in the ICU and ED could participate in the healthy national activity, which would likely enhance their spirits and decrease emotional exhaustion.

In summary, resolutions to nurse burnout need to be customised to the particular group of healthcare professionals. [7] The focus should be, what are the underlying problems of the different groups, [7] for example, in Rwanda having the time to take off work to attend the Friday 3 pm sport ritual is vital to the participants in this study population. In a recent systematic review, fourteen interventions were focused on the individual, and four focused on the individual and occupational interventions. [35]

\section{Limitations}

This study showed the situation of only one referral hospital in the capital city, as it was an explorative qualitative study with no intention to generalise but to inform a larger quantitative study for generalisation. Furthermore, the nurses may have been tired at the time of the focus group discussions, as they had just finished work on the ICU and ED units after a 12-hour work shift.

\section{Recommendations}

1. This study, through its participants, recommends the promotion of a more conducive work environment, appropriate utilisation of nurses with specialised training in Critical Care and Trauma and provision of relaxation time including social support from peers and supervisors. A conducive healthy environment can be achieved by reducing high nurse workload in ICU and ED. Use of standard norms for ICU and ED staffing, based on best practice or benchmarking similar to other countries like South Africa, United States, United Kingdom and Australia and promote efficiency in Emergency Departments to avoid crowing and unpredictability.[36-41]

2. Rwanda has recently introduced a specialisation in Critical Care and Trauma Nursing together with other specialisations. This, not being the first initiative on Critical Care and Trauma Nursing denote a reasonable number to staff the ICUs and Emergency Departments. Perhaps the products of this programme could be better utilised in the Critical Care Units and Emergency Departments of Rwanda. Perhaps the next study should track the graduates of this programme and establish their utilisation in the respective units.[42]

3. The motivation of staff by the provision of regular break time and recognition of extra hours worked. 
Extra hours should be recorded and nurses given the opportunity to take them later or be paid overtime for them if the hospital budget allows. The participants asserted that motivation would play on their psyche. [43] In addition, they could help organise time for sport on Fridays at 3 PM and other events, such as a picnic or other excursion where nurses could relax together. Not everyone will be able to attend at one time, so a roster should be planned, so every nurse gets a chance to attend one event or another.

4. Empowering nurses on procurement and effective communication including in order to make sure that they have an adequate and constant supply of operational materials and equipment.[44]

5. Accommodation in the work schedule for regular debriefing sessions, so that ICU and ED nurses can discuss stress promptly and test shared solutions.[44]

6. Perhaps the unit on Care of the Carer and healthy work environment must now get more attention in education programs and be applied in clinical practice. Specialised nurses could lead the way by initiating a discussion on organisational and self-care activities to prevent stress and burnout.[44,45]

7. Further research could involve a countrywide sample to inform interventions that may benefit the whole health care system in Rwanda. Future research should also address other high-risk departments, such as oncology, theatre, neonatal and paediatrics.

\section{Conclusion}

The study participants in ICU and ED perceived high burnout among themselves at a referral hospital in Kigali. The nurses need to be taken care of too: A good working environment concerning adequate staffing, specialty training, adequate operational materials, and time for regular social activities is needed to improve unit functioning, quality of care and safety, hence patient satisfaction.

\section{Acknowledgements}

We acknowledge the participants for their generous participation and contribution to the knowledge that may inform the profession in its endeavours to improve performance. Thank you to Dr Pamela Meharry for her support with this publication through the Writing Retreats.

\section{Authors' contributions}

EUC, RS and BRB conceptualised and designed the study. EUC collected data. EUC and BRB analysed the data. Drafting of the manuscript: EUC, RS, BRB, MJT and MMJ. A critical review of the manuscript Revision of the content EUC, RS, BRB, MJT and MMJ. All authors read and approved the final manuscript: EUC, RS, BRB, MJT and MMJ.

This article is published open access under the Creative Commons Attribution-NonCommercial NoDerivatives (CC BY-NC-ND 4.0). People can copy and redistribute the article only for noncommercial purposes and as long as they give appropriate credit to the authors. They cannot distribute any modified material obtained by remixing, transforming or building upon this article. See https:// creativecommons.org/licenses/by-nc-nd/4.0/

\section{References}

1. Dyrbye LN, Shanafelt TD, Sinsky CA, Cipriano PF, Bhatt J, Ommaya A, West CP, Meyers D (2017) Burnout Among Health Care Professionals A Call to Explore and Address This Underrecognized Threat to Safe, High-Quality Care NAM Perspectives. Discussion Paper, National Academy of Medicine, Washington, DC. 1-11

2. Zhang X, Huang D, Guan P (2014) Job burnout among critical care nurses from 14 adult intensive care units in northeastern China: a cross-sectional survey. BMJ 4:1-8

3. Chuang C, Tseng P, Lin C, Lin K, Chen Y (2016) Burnout in the intensive care unit professionals. Medicine (Baltimore) 95:1-12

4. Harkin M, Melby V (2014) Comparing burnout in emergency nurses and medical nurses. Clin Nurs Stud 2:152-163

5. Heeb J, Haberey-knuessi V (2014) Health Professionals Facing Burnout: What Do We Know about Nursing Managers? 2014:

6. Kompanje EJO (2018) Burnout, boreout and compassion fatigue on the ICU: it is not about work stress, but about lack of existential significance and professional performance. Intensive Care Med 44:690-691

7. Leiter M, Maslach C (2016) Latent burnout profiles : A new approach to understanding the burnout experience. Burn Res 3:89-100

8. Papazian L, Sylvestre A, Herridge M (2018) Should all ICU clinicians regularly be tested for burnout? Yes. Intensive Care Med 44:681-683

9. Poghosyan L (2010) Nurse Burnout and Quality of Care: Cross-National Investigation in Six Countries. Res Nurs Heal 33:288-298

10. Cimiotti JP, Aiken LH, Sloane DM, Wu ES (2012) Nurse staffing, burnout, and healthcare-associated infection. Am J Infect Control 40:486-490

11. Toh SG, Ang E, Devi MK (2012) Systematic review on the relationship between the nursing shortage and job satisfaction, stress and burnout levels among nurses in oncology/haematology settings. Int J Evid based Heal care 10:126-141

12. PolitDF, Beck CT (2017) Nursing research. Generating and assessing evidence for Nursing Practice, a 10th edition. Lippincott Williams\& Wilkins

13. Braun V, Clarke V (2006) Using thematic analysis in psychology. Qualitative Research in Psychology.

14. Van Der Colff JJ, Rothmann S (2014) Burnout of registered nurses in South Africa. J Nurs Manag 22:630-642

15. Steenkamp JG (2014) Investigating the psychological and social predictors of burnout among nurses. Stellenbosch University 
16. Sibanda S (2015) Examining the psychological and social predictors of burnout among nurses employed by the government. A study of nurses at Gweru provincial hospital, Zimbabwe. Midlands State University

17. Chitura M, Chitura D (2014) Burnout in intensive Unit care unit nurses in Zimbabwe. Eur Sci J 7881:436-457

18. Lasebikan VO, Oyetunde MO (2012) Burnout among Nurses in a Nigerian General Hospital : Prevalence and Associated Factors. ISRN Nurs 2012:1-6

19. Khamisa N, Peltzer K, Oldenburg B (2013) Burnout in Relation to Specific Contributing Factors and Health Outcomes among Nurses : A Systematic Review. Int J Environ Res Public Health 10:2214-2240

20. Elshaer MSN, Aly Moustafa MS, Aiad MW, Eldesoky Ramadan IM (2018) Job Stress and Burnout Syndrome among Critical Care Healthcare Workers. Alexandria J Med 54:273-277

21. Toh SG, Ang E, Devi MK (2012) Systematic review on the relationship between the nursing shortage and job satisfaction, stress and burnout levels among nurses in oncology/haematology settings. Int $\mathrm{j}$ Evid Based Heal 10:126-141

22. Aiken LH, Cimiotti JP, Sloane DM, Smith HL, Flynn L, Neff DF (2011) Effects of Nurse Staffing and Nurse Education on Patient Deaths in Hospitals With Different Nurse Work Environments. Med Care 49:1047-1053

23. Tucker SJ, Weymiller AJ, Cutshall SM, Rhudy LM, Lohse CM (2012) Stress Ratings and Health Promotion Practices Among RNs A Case for Action. JONA 42:282-292

24. McHugh MD, Ma C (2014) Wage, Work Environment, and Staffing: Effects on Nurse Outcomes. Policy Polit Nurs Pr 15:72-80

25. Wakim N (2014) Occupational Stressors, Stress Perception Levels, and Coping Styles of MedicalSurgical RNs. JONA 44:632-639

26. Alexander L (2014) Burnout: Impact on Nursing and Quality of Care. 1-36

27. Teixeira C, Ribeiro O, Fonseca AM, Carvalho AS (2013) Burnoutin intensive care units - a consideration of the possible prevalence and frequency of new risk factors : a descriptive correlational multicentre study. BMC Anesth 13:1-15

28. Manzano-Garcia G, Ayala J-C (2017) Insufficiently studied factors related to burnout in nursing: Results from an e-Delphi study. PLoS One 12:1-20

29. Qiao Z, Chen L, Chen M, Guan X, Wang L, Jiao Y, Yang J, Tang Q (2016) Prevalence and factors associated with occupational burnout among HIV / AIDS healthcare workers in China : a cross-sectional study. BMC Public Health 16:1-7

30. Hunsaker S, Moughan D, Heaston S (2014) Factors that influence the development of compassion fatigue, burnout, and compassion satisfaction in emergency department nurses. Journal of Nursing Scholarship, 47(2), 186-194. Retrieved from https:// lopes.idm.oclc.org/login? url=http:/ / search. proquest.c. J Nurs Scholarsh 2014 1-19

31. Van der Wath A, van Wyk N, Janse van Rensburg E (2013) Emergency nurses' experiences of caring for survivors of intimate partner violence. J Adv Nurs 69:2242-2252

32. Brady M (2015) Death anxiety among emergency care workers. Emerg nurses 23:32-37

33. Mehrabi T, Azadi F, Pahlavenzadeh S, Meghdadi N (2012) effects of yoga on coping strategies. Iran J Nurs Midwifery Care Unit nurses 17:421-424

34. Maslach C,LeiterMP (2016) Understanding the burnout experience: Recent research and its implications for psychiatry. World Psychiatry 15:103-111

35. Ahola K, Toppinen-Tanner S, Seppanen J (2017) Interventions to alleviate burnout symptoms and to support return to work among employees with burnout: systematic review and meta-analysis. 1-39

36. Pascasie K, Mtshali NG (2014) African Federation for Emergency Medicine African Journal of Emergency Medicine Original Research A descriptive analysis of Emergency Department overcrowding in a selected hospital in Rwanda. African J Emerg Med 4:178-183

37. Davis RM, Pless B (2001) Accidents are not unpredictable. Br Med J 322:1320-1321

38. SASA (2013) South African Society Of Anesthesiologists Practice Guidelines 2012 Revision South African Society of Anaesthesiologists. South Africa J Anesth Analg 19:1-43

39. FICM \&, ICS (2015) Guidelines for the Provision of Intensive Care Services.

40. CICM (2011) Minimum standards for intensive care Units.

41. Adriaenssens J, De Gucht V, Maes S (2015) Determinants and prevalence of burnout in emergency nurses: A systematic review of 25 years of research. Int J Nurs Stud 52:649-661

42. Cancedda C, Cotton P, Shema J, Rulisa S, Riviello R, Adams L V (2018) Original Article Health Professional Training and Capacity Strengthening Through International Academic Partnerships: The First Five Years of the Human Resources for Health Program in Rwanda. Kerman Univ Med Sci 7:1024-1039

43. Mathauer I, Imhoff I (2006) Human Resources for Health Health worker motivation in Africa : the role of non-financial incentives and human resource management tools. Biomed Cent 4:1-17

44. Folscher L-L (2014) Care for the Carers. African J Emerg Med 4:167-169

45. Morton PG, Fontaine DK (2018) Critical Care Nursing : A holistic approach, 11 th ed. Philadelphia : Wolters Kluwer, [2018] C2018 